The University of Maine

DigitalCommons@UMaine

Library Staff Publications

Fogler Library

$10-2017$

\title{
Making the Mission Visible: Altmetrics and Nontraditional Publishing
}

Jennifer Bonnet

University of Maine, jennifer.l.bonnet@maine.edu

Marisa L. Mendez-Brady

University of Maine, marisa.mendezbrady@maine.edu

Follow this and additional works at: https://digitalcommons.library.umaine.edu/lib_staffpub

Part of the Scholarly Communication Commons, and the Scholarly Publishing Commons

\section{Repository Citation}

Bonnet, Jennifer and Mendez-Brady, Marisa L., "Making the Mission Visible: Altmetrics and Nontraditional Publishing" (2017).

Library Staff Publications. 27.

https://digitalcommons.library.umaine.edu/lib_staffpub/27

This Article is brought to you for free and open access by DigitalCommons@UMaine. It has been accepted for inclusion in Library Staff Publications by an authorized administrator of DigitalCommons@UMaine. For more information, please contact um.library.technical.services@maine.edu. 


\section{e emeraldinsight}

\section{Digital Library Perspectives}

Making the mission visible: altmetrics and nontraditional publishing

Jennifer L. Bonnet, Marisa Méndez-Brady,

\section{Article information:}

To cite this document:

Jennifer L. Bonnet, Marisa Méndez-Brady, (2017) "Making the mission visible: altmetrics and nontraditional publishing", Digital Library Perspectives, Vol. 33 Issue: 4, pp.294-304, https:// doi.org/10.1108/DLP-01-2017-0002

Permanent link to this document:

https://doi.org/10.1108/DLP-01-2017-0002

Downloaded on: 23 October 2017, At: 06:10 (PT)

References: this document contains references to 24 other documents.

To copy this document: permissions@emeraldinsight.com

The fulltext of this document has been downloaded 60 times since 2017*

Access to this document was granted through an Emerald subscription provided by emeraldsrm: 194294 []

\section{For Authors}

If you would like to write for this, or any other Emerald publication, then please use our Emerald for Authors service information about how to choose which publication to write for and submission guidelines are available for all. Please visit www. emeraldinsight.com/authors for more information.

\section{About Emerald www.emeraldinsight.com}

Emerald is a global publisher linking research and practice to the benefit of society. The company manages a portfolio of more than 290 journals and over 2,350 books and book series volumes, as well as providing an extensive range of online products and additional customer resources and services.

Emerald is both COUNTER 4 and TRANSFER compliant. The organization is a partner of the Committee on Publication Ethics (COPE) and also works with Portico and the LOCKSS initiative for digital archive preservation.

*Related content and download information correct at time of download. 


\section{DLP}

33,4

\section{4}

Received 3 January 2017 Revised 20 January 2017 Accepted 24 January 2017

\section{Making the mission visible: altmetrics and nontraditional publishing}

\author{
Jennifer L. Bonnet and Marisa Méndez-Brady \\ University of Maine, Orono, Maine, USA
}

(1)

\begin{abstract}
Purpose - Whereas traditional book and journal publishing remain the gold standard for many postsecondary institutions, nontraditional publishing is just as prolific at the flagship university in Maine. The university has strong land and sea grant missions that drive a broad research agenda, with an emphasis on community outreach and engagement. However, the impact of researchers' contributions outside of academe is unlikely to be accurately reflected in promotion, tenure or review processes. Thus, the authors designed a series of altmetrics workshops aimed at seeding conversations around novel ways to track the impact of researchers' diverse scholarly and creative outputs.
\end{abstract}

Design/methodology/approach - This paper presents a case study of the instructional approach taken at the University of Maine library to facilitate discussions of alternative impact assessments that reach beyond traditional publications.

Findings - Evaluations revealed an increased awareness of, and interest in, impact tracking tools that capture both traditional scholarship, like journal articles, and nontraditional scholarly and creative outputs, such as videos, podcasts and newsletters. The authors learned that altmetrics provides an entry point into a broader conversation about scholarly impact, and was best received by those whose scholarly output is not always captured by traditional metrics.

Practical implications - Scholars are equipped with novel methods for describing the value of their work and discovering a broader audience for their research. Future initiatives will target the needs identified through initial conversations around altmetrics.

Originality/value - Altmetrics workshops provide spaces to explore the potential for new tools that capture a range of previously unconsidered measures of impact, and to discuss the implications of those measures.

Keywords Altmetrics, Impact, Institutional repository, Scholarly communication,

Library instruction and outreach, Nontraditional publishing

Paper type Case study

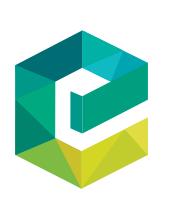

Digital Library Perspectives Vol. 33 No. 4, 2017 pp. 294-304

(C) Emerald Publishing Limited 2059-5816

DOI 10.1108/DLP-01-2017-0002

\section{Introduction}

What is considered scholarship at a rural, land and sea grant university? Whereas traditional book and journal publishing remain the gold standard for many postsecondary institutions, nontraditional publishing is just as prolific at the flagship university in Maine. As a research-intensive institution, familiar outputs like journal articles are produced alongside nontraditional outputs and derivative materials, such as videos, websites, policy documents and newsletters. This broad view of scholarship reflects the university's foundations in the Morrill Act (Library of Congress, 2015), and aligns with a university mission dedicated to public service and outreach within Maine's communities. Campus priorities are manifold, but regional priorities are clear: "Using research-based knowledge, outreach efforts promote sustainable use of Maine's abundant natural resources, and build 
intellectual, cultural, and economic capacity throughout Maine and beyond" (University of Maine, 2010).

An expansive view of scholarly work is challenging in an educational environment that emphasizes traditional publishing structures for promotion, tenure and review. Contributions by researchers to local discussions on everything from public policy and the environment, to public health and community relations, are unlikely to be accurately reflected in evaluations. Alternative metrics, or altmetrics, that focus on tracking the impact of online interactions for a range of academic and non-academic Altmetrics and nontraditional publishing works hold promise for these types of outputs. This paper will discuss the approach that the University of Maine library is taking to raise awareness of altmetrics, in an effort to increase attention to its possible role in assessment. Ultimately, the library hopes to provide support for researchers who are not only publishing on the national stage but also raising the visibility of the university mission at local and regional levels.

\section{Brief overview of altmetrics}

Traditional measures of academic impact tend to rely on citation counts to evaluate the influence of a work within a discipline. This method of impact tracking emphasizes the value of research as it correlates to the publication in which it is disseminated, and reflects the primary mode of scholarly communication throughout the twentieth century: print publication (Roemer and Borchardt, 2015). With the advent of the internet, digital tools have enabled a proliferation of research outputs (Priem and Hemminger, 2010). In this environment, articles are often disaggregated from their publications, and scholarship comes in many forms that are easily published in online communities outside of academe.

This shift in how academics, and the public, view and access scholarly outputs has led to expanded discussions of what impact looks like in the twenty-first century. According to the National Information Standards Organization (2016), scholarly impact is an evolving concept based on the values of diverse stakeholders in the research enterprise. At present, there are calls to move away from prioritizing journals alone as markers of excellence to focus more specifically on article-level metrics (ALMs). When Neylon and $\mathrm{Wu}(2009)$ coined the phrase "article-level metrics" in the Public Library of Science, there were over 800,000 individual articles uploaded to PubMed the previous year. This influx of articles sparked conversations about the need for alternate tools to evaluate article importance and quality.

According to Tanenbaum (2013, p. 4), ALMs have the potential to complement traditional methods of impact tracking by "open[ing] the door to measures of both the immediacy and the socialization of an article". Essential to this evolution of impact tracking is altmetrics, a term conceived by Priem (2010). Altmetrics is a suite of indicators for gauging the impact of scholarly and creative works by attending to how people interact with these works in online environments. Examples include social media sharing through platforms like Facebook, Twitter or Reddit, bookmarking in reference managers like Mendeley, and online mentions or discussions of works in news outlets or policy documents. Several altmetrics tracking services exist with free and fee-based options, including Altmetric (2016), Plum Analytics (2016) and Impactstory (2016). These tools allow stakeholders to track impact from heterogeneous data points, providing insights into a broader swath of scholarly and creative work that can be utilized to meet a diversity of goals (Tanenbaum, 2013; Roemer and Borchardt, 2015). As Priem et al. (2010) stated, "altmetrics will track impact outside the academy, impact of influential but uncited work and impact from sources that are not peer-reviewed". 
DLP

33,4

296

\section{Background}

Altmetrics' capacity for identifying impact beyond traditional modes of publication and outreach is beginning to resonate with researchers at the University of Maine. This is largely due to a university environment where much of the nontraditional publishing activity has an underlying focus on creating works that are accessible to communities throughout the state. Scholarly and creative outputs may include videos on how to harvest seasonal fruits, podcasts about science instruction in higher education, news articles on presidential politics or white papers on community-university solutions to local problems. This diversity of outputs raises questions about how best to capture and display the impact that these contributions have within academic and non-academic communities (Figure 1).

The nature of these works poses challenges to the measurement-driven approach within many promotion, tenure and review processes. Most measurements that focus on bibliometrics are geared toward traditional scholarly works, such as journal articles. Recent conversations among University of Maine librarians, staff and faculty have revealed a desire to meaningfully assess the scope and variety of researchers' scholarly and creative outputs beyond the journal article alone. However, there is a paucity of awareness regarding the use of altmetrics and its potential to contribute to the impact stories of campus researchers, departments, colleges and units.

To address this gap, two university librarians designed an introductory workshop to familiarize campus constituents with the goals of altmetrics, and to underscore the potential of the social web in capturing insights into scholarly influence beyond academe. Building on this initial workshop, the authors collaborated with the campus's Cooperative Extension office to tailor two additional workshops to their specific needs. The authors hope to continue providing similarly situated altmetrics workshops to help university partners communicate scholarly findings and identify methods for measuring their impact.

\section{Initial approach}

In May 2016, the University of Maine library provided an altmetrics workshop to interested faculty, staff and students that centered on the relationship between scholarly impact

Figure 1.

Experiment station video on fruit harvesting in Maine

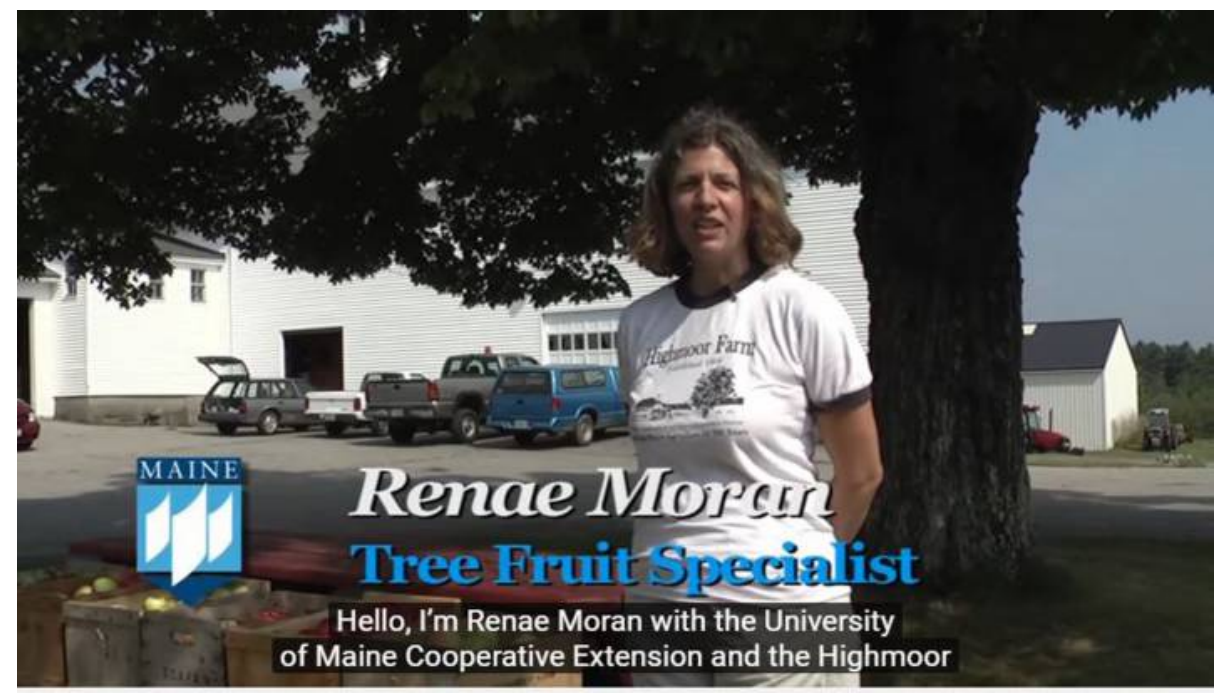




\section{Book Metrics}

66. Citations
17 Readers
35 SpringerLink Ebooks
Search for a book, click on "About this Book," and view the Book Metrics on the right side of
the page.

CINAHL

In your search results, a PlumX icon will appear. When you hover over it, you will see a variety of metrics caiculations. Click on "see details" to get additional information. Additional EBSCO databases are planning to incorporate Plum $\times$ metrics (date TBD) tracking and the social web. The workshop began with an overview of the bibliometric tools commonly used in scholarly communication, an introduction to altmetrics as a complementary tool to traditional impact measures, and a discussion on ways altmetrics can function within and beyond the university landscape. The librarians then shared examples of how altmetrics is applied to content in library databases and to the university's institutional repository (IR). To conclude the workshop, attendees participated in a facilitated discussion of the potential advantages and drawbacks of altmetrics implementation and use (Figure 2).

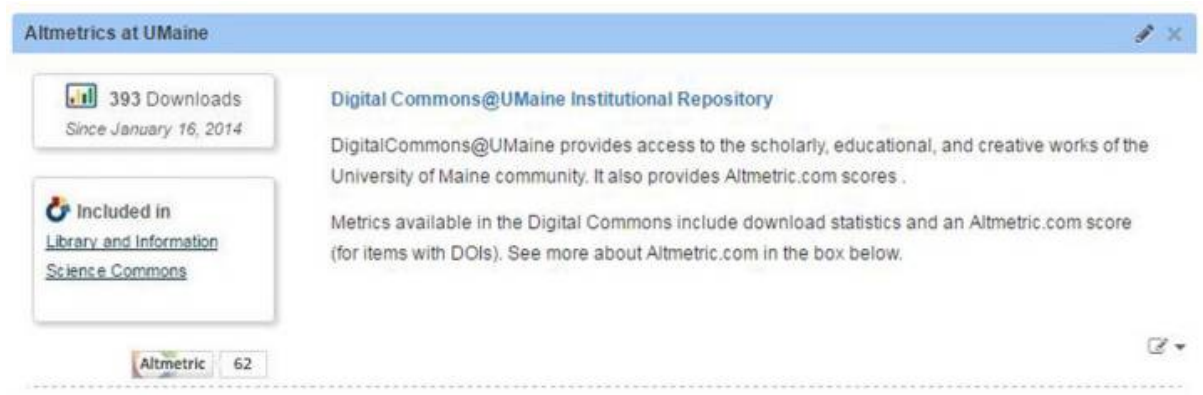

\section{Proquest Databases}

Click on the abstract or title to see the altmetric score on the bottom right of the page.

\section{IEEE Explore}

Click on the abstract or title to see the altmetric score

on the bottom right of the page.

One Search

Search engine that draws in literature on many topics from a

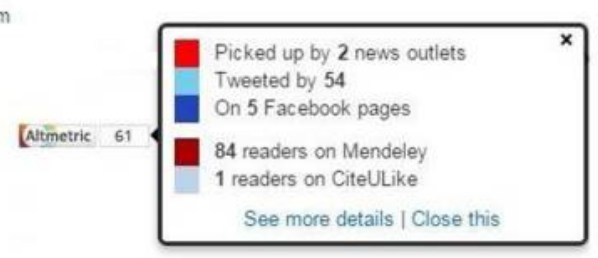

variety (but not all) of the Fogler Library collections. The altmetric

score is visible in the results list.

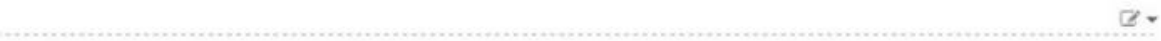

Altmetrics and nontraditional publishing 
DLP

33,4

298

Indispensable to any workshop or library event is publicity. Given the novelty of altmetrics, the librarians worked with the library's public relations manager to create visually appealing yet informative marketing materials (Figures 3 and 4).

Workshop participants included disciplinary faculty from Anthropology, Communication and Journalism, Economics, Forestry, Marine Sciences, Climate Science and Engineering, as well as Cooperative Extension faculty, several librarians and multiple graduate students in Anthropology and Journalism. Many of the attendees worked in areas that share research goals related to meeting the needs of Maine communities, with outcomes aimed at both scholarly and non-scholarly audiences. This diverse gathering of researchers succeeded in seeding a conversation about the role of scholarly impact beyond the university, and produced compelling questions, such as:

Q1. How does one get buy-in from senior personnel for new approaches to impact tracking?

Q2. Is altmetrics better suited to applied work or a general audience, versus scholarly publications?

Q3. Does the slower pace of publication and diffusion in the humanities create a bias in altmetrics scores?

Q4. Would universities with more money and public relations staff have higher scores?

Many of the questions mirrored a general consensus that emerged in the evaluations: altmetrics was a new and intriguing concept:

- "Honestly, the entire concept was brand new to me".

- "I wasn't familiar with altmetrics, so it was all useful".

- "This was a great introduction to what altmetrics can do, and where it might also be heading in the future".

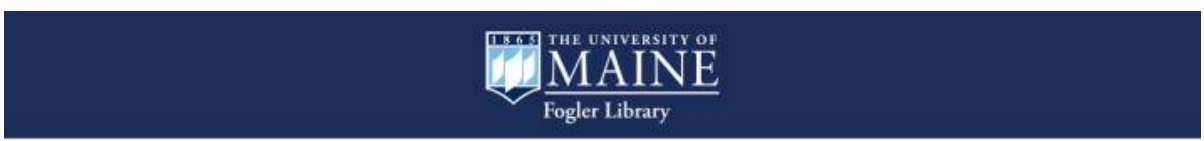

Is your research popular on...

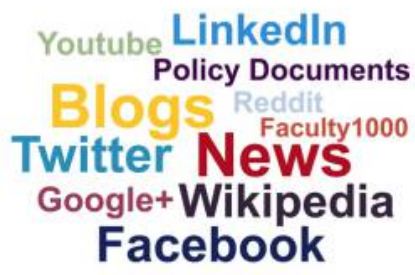

Altmetrics: Scholarly Impact on the Social Web

Join UMaine librarians to find out more about how your work is perceived online. At the workshop, you will learn:

O Ways in which scholarly impact is evolving

o How to use altmetrics to supplement your publication impact

Where to find altmetrics in UMaine resources

- How deliverables can create a researcher identity online

When: Tuesday, May 10th, 10-11am

Where: Library Classroom, Fogler Library

Who: Marisa Méndez-Brady, Science Librarian Jen Bonnet, Social Sciences \& Humanities Librarian
Figure 3.

Altmetrics workshop flyer 1 


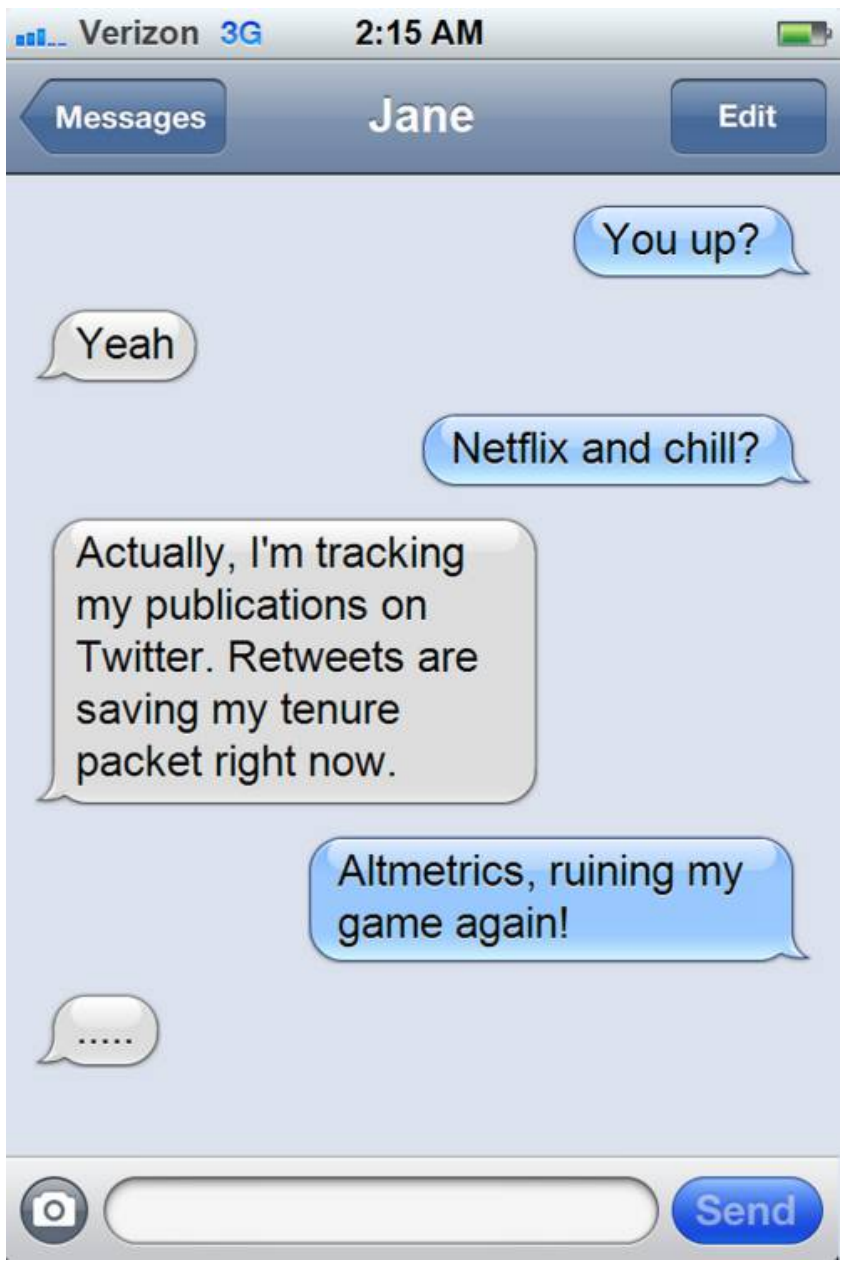

Altmetrics and nontraditional publishing

Beyond the newness of altmetrics, evaluations demonstrated enthusiasm among participants for laying additional groundwork:

- "The workshop was great and I'm now motivated to contact [my subject librarian] and work on my on-line research presence”.

- 'I wonder if having another workshop that covered more of the 'how to's?' such as how to take a scholarly work from start to finish starting with adding it to the digital commons and getting it a DOI to then tracking using altmetrics [sic]".

At the workshop's conclusion, a Cooperative Extension Program Administrator requested specialized altmetrics training geared specifically to her staff. The Cooperative Extension at the University of Maine consists of a network of researchers and practitioners that primarily produces nontraditional outputs meant to serve local populations. The Program Administrator immediately identified altmetrics as an innovative approach to showcasing 
DLP 33,4

her staff's impact within the communities they serve. As their mission statement notes, this campus unit strives "to help Maine people improve their lives through an educational process that uses research-based knowledge focused on issues and needs" (University of Maine Cooperative Extension, 2000). Cooperative Extension faculty and staff achieve these objectives through partnerships with local businesses, agricultural organizations, industry leaders and community members. In response, the librarians designed a pair of additional workshops for this specialized network.

\section{Follow-up workshops}

Specific training for Cooperative Extension faculty and staff took the form of a two-part workshop series. Two-hour workshops were provided on separate, consecutive days and were designed with the knowledge that a primary goal for Extension researchers is to make their findings available to the local community. The intersection between self-archiving and altmetrics was made explicit, as was the possibility for increased visibility of outputs in multiple contexts.

The first session was similar to the one described previously. The librarians focused on novel ways to track impact online and to assess the reach of diverse types of scholarly and creative outputs. Altmetrics is especially resonant for Cooperative Extension given that traditional bibliometric methods for measuring impact do not always serve the types of publications they produce. For this workshop, the librarians added a section about scholarly communication workflows and how the research life cycle can be a guide to thinking holistically about altmetrics and impact assessment (Figure 5).

The second session focused on making research findings available to the local community through the University's IR, Digital Commons (University of Maine, 2016). An IR staff member facilitated this hands-on workshop, which included: instruction on the goals of the IR, steps to submitting materials, and time for participants to upload content. At the end of the session, there was a discussion of the role of good metadata in optimizing the discoverability and trackability of one's work, and participants were given time to ask questions.

Key insights from evaluations of this series revealed that the IR is a preferred platform for publishing. Participants were keen to learn that the IR could accommodate two sets of alternative metrics related to their publications: data gathered through Google Analytics (e.g., usage data and site traffic), and social web data gathered through altmetrics. At the same time, the librarians learned that although many Extension faculty make derivative works from their published findings, and dissemination of this work is paramount, it is the administrative staff that are responsible for making these derivatives available to stakeholders.

It was then no surprise to learn from evaluations that additional training in the use of the IR would benefit administrative staff. This additional training will go a long way in building the volume of Extension content and expanding impact tracking ability. Evaluations also signaled an appreciation of the range of expertise and support available through the library, which will open the door for future discussions around scholarly communication:

- "A shorter version of this for admin staff would be helpful since they may do a lot of the postings".

- "Thank you for the great support you offer us all in Extension! I am so in awe of the resources and people available at [the library] to help support the work we do thank you!"

Outside of the evaluations, the workshop itself revealed variation in participants' knowledge of impact metrics and of digital platforms more broadly. Whereas altmetrics provides an entry point into a broader scholarly conversation, it is clear that additional insights into the 


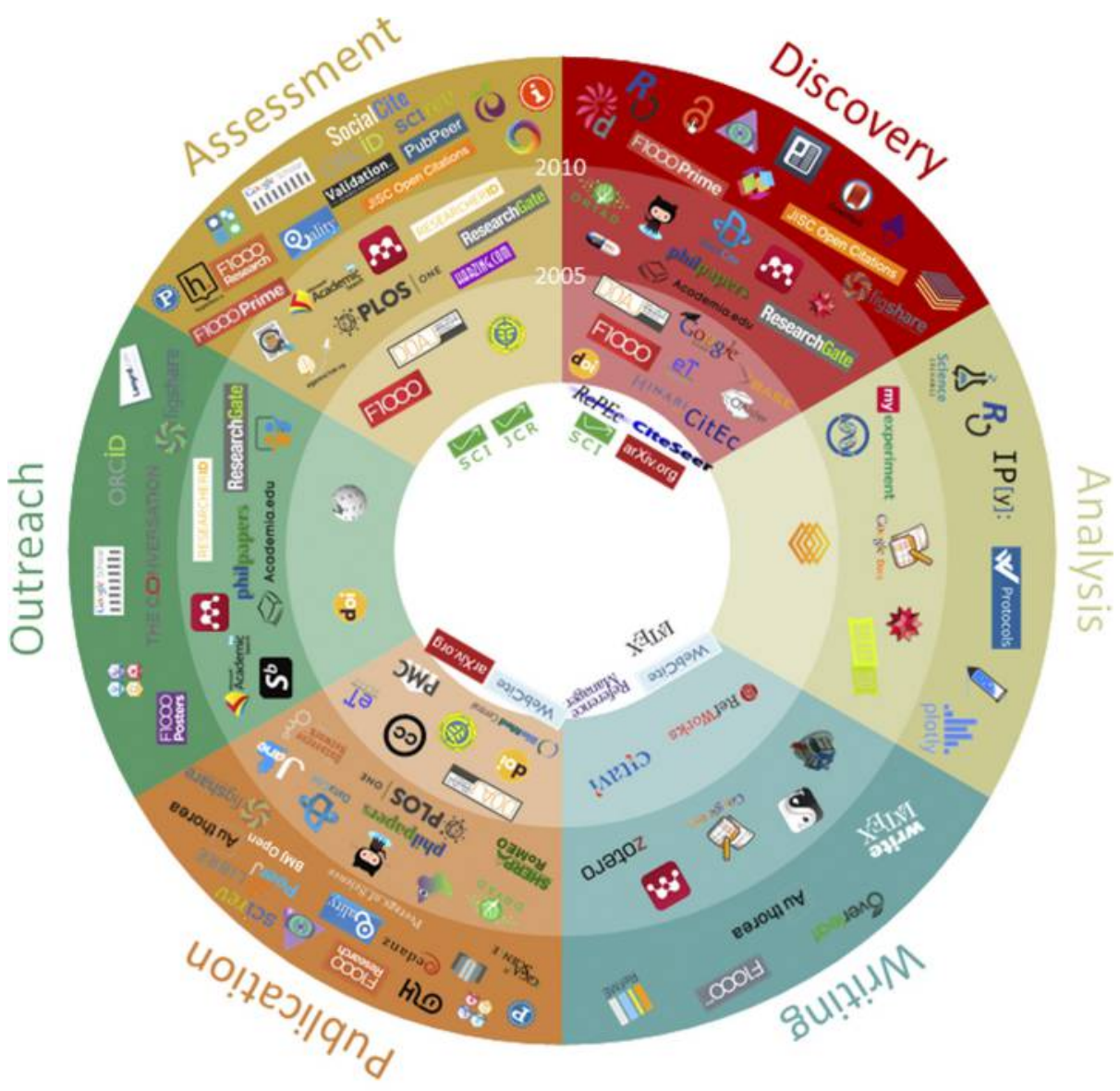

Altmetrics and nontraditional publishing

301

Source: https://innoscholcomm.silk.co

Figure 5.

Research life-cycle data card from innovations in scholarly communications 101

fundamentals of scholarly communication would be beneficial to our campus population. Looking toward the future, it would be helpful to provide additional background information on impact tracking, open access and the various methods for publishing nontraditional works. Offering workshops that address common methods and tools used in scholarly communications would allow campus scholars to evaluate how altmetrics might fit into their assessments.

\section{Discussion}

For University of Maine researchers whose work is not well captured through traditional bibliometrics, altmetrics has considerable potential. The altmetrics workshops succeeded not only in facilitating an appreciation for impact tracking on the social web, but also an understanding of how heterogeneous outputs fit into academic workflows. Analyzing these outputs through the lens of assessment provides an avenue for measuring the reach of scholarly and creative works in an online environment (Tanenbaum, 2013), and is one way 
DLP

33,4

for librarians to promote platforms that can help give visibility to datasets, publications, non-traditional scholarly objects and self-published works such as those in the University of Maine's IR.

Although there are mission-driven centers that have been utilizing University of Maine's Digital Commons for publication and outreach, most notably the Margaret Chase Smith Policy Center (Margaret Chase Policy Center, 2016a) through its publication, Maine Policy Review (Margaret Chase Policy Center, 2016b), University of Maine's IR has not factored into the workflows of most researchers who participated in the altmetrics workshops. However, after attending the May 2016 session, key faculty members involved with the Senator George J. Mitchell Center for Sustainability Solutions spearheaded an effort to include the IR into their workflow. Similar to the Cooperative Extension, the Mitchell Center's mission statement is rooted in the University of Maine's public service mission (see http://umaine.edu/mitchellcenter/ about/at-a-glance).

Not only did the Mitchell Center create an instance in the IR, but they also hired a student employee to assist with the time-consuming process of uploading documents with the appropriate metadata for discoverability. Utilizing the IR for green open access measures increases the visibility of community engagement outside of academe (Konkiel, 2014). Additionally, making the research output of the Mitchell Center available to the public through self-archiving allows for an increased ability to measure the Center's impact beyond traditional bibliometrics. The newly created IR instances for both the Mitchell Center and Cooperative Extension illustrate the librarians' success in advancing their position as a supportive partner in the research enterprise.

\section{Conclusion}

The diversification of research demands that librarians enable researchers to distinguish the various ways they are able to communicate scholarly impact within and beyond higher education. Altmetrics outreach provides a platform through which librarians can familiarize university partners with different types of metrics that factor into the academic environment, and help researchers optimize the measurable impact of their work. Altmetrics is ideally situated to facilitate conversations that address an increasingly broad array of assessment tools because the metrics themselves vary, taking into account data points from multiple communities on the web (Priem et al., 2010). For many campus centers, altmetrics has the potential to render visible measurements of community impact outside of academe that account for a range of faculty outreach often missing from traditional bibliometric assessments (Bornmann, 2014).

The library's role in facilitating connections between how research is disseminated and which metrics may illustrate impact is becoming more relevant within the profession at-large (Roemer and Borchardt, 2015). At the University of Maine, librarians are just entering this dialogue. Altmetrics workshops have provided opportunities to help researchers consider a range of impact measures and outline workflows that meet their personal and professional goals. Engaging with these researchers has allowed librarians to gain a better understanding of how campus partners utilize scholarly tools and has expanded conversations about research publishing and dissemination. Future initiatives include a semester-long scholarly communication workshop series and a half-day conference. These efforts show promise for a variety of departments and centers within and outside of campus, and buy-in is growing. As the library continues to become attuned to the needs of a diverse 
constituency, it is clear that the land and sea grant missions that are woven into the fabric of research at the University of Maine position altmetrics to sit at the center of nontraditional scholarly impact.

\section{References}

Altmetric (2016), available at: www.altmetric.com (accessed 13 January 2017).

Bornmann, L. (2014), "Do altmetrics point to the broader impact of research? An overview of benefits and disadvantages of altmetrics", Journal of Informetrics, Vol. 8 No. 4, pp. 895-903.

Impactstory (2016), available at: https://impactstory.org (accessed 13 January 2017).

Konkiel, S. (2014), "The right metrics for generation open: a guide to getting credit for open science", available at: http://blog.impactstory.org/right-metrics-generationopen-post (accessed 15 August 2016).

Library of Congress (2015), "Primary documents in American history: Morrill Act", available at: www. loc.gov/rr/program/bib/ourdocs/Morrill.html (accessed 20 July 2016).

Margaret Chase Policy Center (2016a), "Home page", available at: https://mcspolicycenter.umaine.edu (accessed 5 December 2016).

Margaret Chase Policy Center (2016b), "Maine policy review", available at: http://digitalcommons. library.umaine.edu/mpr (accessed 5 December 2016).

National Information Standards Organization (2016), "Outputs of the NISO alternative assessment metrics project", available at: www.niso.org/apps/group_public/download.php/17091/NISO\% 20RP-25-2016\%200utputs $\% 20$ of $\% 20$ the $\% 20$ NISO $\% 20$ Alternative $\% 20$ Assessment $\% 20$ Project. pdf (accessed 22 September 2016).

Neylon, C. and Wu, S. (2009), "Article-level metrics and the evolution of scientific impact", PLoS Biology, Vol. 7 No. 4, doi: 10.1371/journal.pbio.1000242.

Plum Analytics (2016), available at: http://plumanalytics.com (accessed 13 January 2017).

Priem, J. (2010), available at: https://twitter.com/jasonpriem/status/25844968813.

Priem, J. and Hemminger, B. (2010), "Scientometrics 2.0: new metrics of scholarly impact on the social web", First Mondav, Vol. 15 No. 7, doi: 10.5210/fm.v15i7.2874.

Priem, J. Taraborelli, D. Groth, P. and Neylon, C. (2010), "Almetrics: a manifesto", available at: http:// altmetrics.org/manifesto (accessed 15 July 2016).

Roemer, R.C. and Borchardt, R. (2015), Meaningful Metrics: A 21st Century Librarian's Guide to Bibliometrics, Altmetrics, and Research Impact, Association of College \& Research Libraries, Chicago, IL.

Tanenbaum, G. (2013), “Article-level metrics: a SPARC primer”, available at: http://sparcopen.org/ourwork/article-level-metrics (accessed 5 July 2016).

University of Maine (2010), "Mission", available at: https:/umaine.edu/about/mission-2 (accessed 5 December 2016).

University of Maine (2016), “DigitalCommons@UMaine”, available at: http://digitalcommons.library. umaine.edu (accessed 15 November 2016).

University of Maine Cooperative Extension (2000), "Mission, vision, goals, guiding principles, values and norms", available at: http://extension.umaine.edu/plugged-in/policies-guidelines/policiesprocedures-manual/section-one-organization/1-1 (accessed 5 December 2016).

\section{Recommended sources}

Bartling, S. and Friesike, S. (2014), Opening science: The evolving guide on how the Internet is Changing Research, Collaboration and Scholarly Publishing, Springer International Publishing, Cham.

Altmetrics and nontraditional publishing 
DLP 33,4

Croft, R., Reed, K. and McFarland, D. (2015), "Interrogating impact: Altmetrics as indicators of influence in and beyond the academy", available at: https://viuspace.viu.ca/handle/10613/2510 (accessed 5 July 2016).

Cronin, B. and Sugimoto, C.R. (2014), Beyond Bibliometrics: Harnessing Multidimensional Indicators of Scholarly Impact, MIT Press, Cambridge, MA.

Hammarfelt, B. (2014), "Using altmetrics for assessing research impact in the humanities", Scientometrics, Vol. 101 No. 2, pp. 1419-1430.

Holmberg, K. (2016), Altmetrics for Information Professionals: Past, Present and Future, Chandos Publishing, Amsterdam.

Priem, J. Piwowar, H.A. and Hemminger, B.M. (2012), "Altmetrics in the wild: using social media to explore scholarly impact”, available at: https://arxiv.org/abs/1203.4745 (accessed 5 July 2016).

\section{Corresponding author}

Jennifer L. Bonnet can be contacted at: jenbonnet@maine.edu

For instructions on how to order reprints of this article, please visit our website: 